\title{
Annotations
}

\section{Have parents the right to see their children's medical reports?}

There can be few people who do not feel threatened by someone talking about them behind their backs. The same feelings are aroused by written reports and most of us have suffered from school reports, though, hopefully, few parents would keep these from their children.

A medical report is a communication from one doctor to another or from a doctor to a professional in another discipline. Its aim is to communicate important information about the patient, in this case a child. Being a communication it should be helpful, informative, and above all understandable.

The family doctor's letter written to the consultant when referring a patient for his opinion is quite likely to be steamed open if given to the patient sealed. It would be preferable, therefore, to send the letter by post if privacy were essential or to leave the envelope unsealed if handed to the patient.

It is relevant to study the arguments on this subject raised by both sides. Doctors feel that their report is a private communication between professionals which must be able to contain all the information about the child and his family, even if some of this is derogatory. If doctors had to censor what they wrote they might easily be forced to omit important details. Moreover, because it is written in technical language the parent will fail to understand its meaning and may well misinterpret what is written.

The main concern of parents (or patients) is that the report may contain inaccurate information which they have no chance of checking and correcting. They believe that doctors would be more careful in their record keeping if they knew that parents had the right to see the document. There is no doubt that secrecy sours the relationship between patient and doctor and it assumes parents are unable to accept facts relating to their own lives which in any case are likely to have come from information they supplied to the doctor. Secrecy also suggests that it is a method of protecting the doctor from legal action for negligence.

At present, parents do not have unqualified access to medical reports on their children but there is no clear cut ruling. The proposal that this should be of right is to help parents, thtreby ensuring cooperation between both parties. This requires that the report should be written in intelligible language which also ensures that it is understood by the professionals as well as the parents. Some professionals communicate in their own jargon which is incomprehensible to professionals from another discipline.

Since the reading of the report by the parents aims to help them as well as the professionals it should contain material, written with sensitivity, which will increase the parents understanding of the problem. The discussion during the consultation can be reinforced by a letter. This aspect is also advantageous to the parents who can discuss with their doctor aspects of the consultation or letter which are not clear to them.

In this issue of the Archives Dr Partridge discusses his method of writing reports for parents whose children attend the Warwick Child Development Centre. The report on a handicapped child is an excellent example of the problem because parents are very sensitive to the disorder, while the document contains a number of different reports written by team members from different disciplines. At Charing Cross Hospital Child Development Centre we also, for many years, have been providing parents with a letter, though with certain differences from the methods described by Dr Partridge.

These differences are relevant to the subject of this annotation. It would seem that at Warwick, parents do not attend the final case conference whereas at Charing Cross they do. This means that they may well have heard differences of opinion being discussed by professionals and taken part in the discussion themselves. This can be difficult for parents but over the years, by detailed explanation of the issues at stake and an explanation of the reasons for the final agreed decision reached. parents have benefitted. They have seen the steps and the time taken to work out what is believed to be best for their child and been involved in the discussion.

In Warwick the parents are told the results of the conference at a separate meeting with the paediatrician and the key worker. After this the report is written and then delivered to the home by the key 
worker, who reports back to the team on the reaction of the parents. Since the report is taken to the home it could presumably be studied first by one parent alone, if the other were out. This report includes some of the original reports by the professionals but others are omitted if they do not wish to contribute.

At Charing Cross the letter is compiled by the senior registrar in developmental paediatrics and embodies the findings of all members of the team together with the agreed plan of management. We find that a letter incorporating all the views but not written in report form is more intimate and more easily understood by the parents. Moreover, since it is sent by post it is studied by both parents before their next visit to the centre. A copy of this letter is included with the full technical report sent to the general practitioner, an aspect explained to the parents who can, therefore, discuss it with the general practitioner knowing he has a copy.

It is clear that both centres believe in compiling a report for the parents, who tell us how much it helps them. It is not so much the parents having a report by right as needing a comprehensible, written communication about their child's problems and plans for future management.

Other methods are used by other doctors to convey to parents the contents of a medical report. One paediatrician dictates his letter to the family doctor in the presence of the parents. Another addresses his letter to the child, sending a copy to the general practitioner.

I believe that parents have a right to see the medical reports on their children but the writer of the report must know beforehand that his report may be shown to the parents and his agreement must be obtained. As far as possible the report should be shown to the parents when a doctor is present so that he can immediately answer any queries raised. A report seen by parents alone is liable to cause anxieties and often an aggressive reponse from lack of explanation and ignorance of terms used.

It is also my belief that a medical report should only be sent to another medical practitioner; unless parental permission has been obtained for it to go to a professional from a different discipline. I am very concerned that a child who has had a febrile convulsion when much younger may have the term 'epilepsy' recorded on an educational document which could affect his later employment.

The guiding principle is to act to the benefit of the parents or patient. For this reason I am in favour of patients keeping their own notes and taking them from doctor to doctor. With this method, doctors are careful what they write and notes are never lost.

In my medical school the student reads his report from his teacher at the end of a term and then signs it. I consider that parents should have the same right to read medical reports on their children. I believe this would reduce their anxiety, increase their understanding of the problem, and help them to talk to their doctor with greater ease, thereby benefitting the child and his family.

\section{Reference \\ ${ }^{1}$ Jolly H. Child development centre. In: Rose FC, ed. Paediatric neurology. Oxford: Blackwell Scientific, 1979:98-106.}

Hugh Jolly Department of Paediatrics, Charing Cross Hospital, London W6 8RF

The subject of written assessment reports for parents is discussed by $\mathrm{J}$ W Partridge on pages 678-681. 